\title{
A new Maastrichtian species of the centrosaurine ceratopsid Pachyrhinosaurus from the North Slope of Alaska
}

\author{
Anthony R. Fiorillo and Ronald S. Tykoski \\ Acta Palaeontologica Polonica 57 (3), 2012: 561-573 doi: http://dx.doi.org/10.4202/app.2011.0033
}

The Cretaceous rocks of the Prince Creek Formation contain the richest record of polar dinosaurs found anywhere in the world. Here we describe a new species of horned dinosaur, Pachyrhinosaurus perotorum that exhibits an apomorphic character in the frill, as well as a unique combination of other characters. Phylogenetic analysis of 16 taxa of ceratopsians failed to resolve relationships between $P$. perotorum and other Pachyrhinosaurus species ( $P$. canadensis and $P$. lakustai). $P$. perotorum shares characters with each of the previously known species that are not present in the other, including very large nasal and supraorbital bosses that are nearly in contact and separated only by a narrow groove as in $P$. canadensis, and a rostral comb formed by the nasals and premaxillae as in P. lakustai. P. perotorum is the youngest centrosaurine known (70-69 Ma), and the locality that produced the taxon, the Kikak-Tegoseak Quarry, is close to the highest latitude for recovery of ceratopsid remains.

Key words: Dinosauria, Centrosaurinae, Cretaceous, Prince Creek Formation, Kikak-Tegoseak Quarry, Arctic.

Anthony R. Fiorillo [anthony.fiorillo@perotmuseum.org] and Ronald S.

Tykoski [ron.tykoski@perotmuseum.org], Museum of Nature and Science, Dallas, P.O. Box 151469, Dallas, TX 75315-1469, USA.

This is an open-access article distributed under the terms of the Creative Commons Attribution License (for details please see creativecommons.org), which permits unrestricted use, distribution, and reproduction in any medium, provided the original author and source are credited. 
Far Full text $(657.1 \mathrm{kB})$ ।

FoF Supplementary file $(51.0 \mathrm{kB})$ 